\title{
Supplemental vitamin D and physical performance in COPD: a pilot randomized trial
}

This article was published in the following Dove Press journal:

International Journal of COPD

14 February 2013

Number of times this article has been viewed

\author{
Sonja M Bjerk' \\ Bradley D Edgington' \\ Thomas S Rector ${ }^{1,2}$ \\ Ken M Kunisaki ${ }^{1,2}$ \\ 'University of Minnesota, \\ 2Minneapolis VA Health Care \\ System, Minneapolis, MN, USA
}

Correspondence: Ken Kunisaki Minneapolis VA Health Care System, Pulmonary Section ( I I IN),

One Veterans Drive, Minneapolis,

MN 554I7, USA

Tel + I 6124674400

Fax + I 6127275634

Email kunis00I@umn.edu
Background: Low 25-hydroxyvitamin D (25[OH]D) levels, commonly observed in chronic obstructive pulmonary disease (COPD), are associated with muscle weakness in elderly populations, and vitamin D supplementation appears to improve muscle strength and decrease falls in older individuals. We tested the effect of vitamin D supplementation on physical performance in patients with COPD.

Methods: Patients were randomized to daily cholecalciferol (2000 IU) or placebo for 6 weeks. The primary outcome was the 6-week change in Short Physical Performance Battery (SPPB) score. Secondary outcomes included changes in the St George's Respiratory Questionnaire (SGRQ) score, and serum 25(OH)D.

Results: Thirty-six participants (mean age 68 years, all Caucasian males, mean forced expiratory volume in one second $33 \%$ of predicted) completed the study. Despite an increase in $25(\mathrm{OH}) \mathrm{D}$ levels in the intervention arm to a mean of $32.6 \mathrm{ng} / \mathrm{mL}$ (versus $22.1 \mathrm{ng} / \mathrm{mL}$ in the placebo arm), there was no difference in improvements in either SPPB scores $(0.3$ point difference; $95 \%$ confidence interval -0.8 to $1.5 ; P=0.56$ ) or SGRQ scores $(2.3$ point difference; $95 \%$ confidence interval -2.3 to $6.9 ; P=0.32$ ).

Conclusion: Among patients with severe COPD, 2000 IU of daily vitamin D for 6 weeks increased 25(OH)D to a level widely considered as normal. However, compared with placebo, short-term vitamin D supplementation had no discernible effect on a simple measure of physical performance.

Keywords: chronic obstructive pulmonary disease, randomized controlled trial, vitamin D, skeletal muscle strength

\section{Introduction}

Severe chronic obstructive pulmonary disease (COPD) has a major adverse impact on quality of life and overall health status, with exercise intolerance being a major complaint. In addition to ventilatory limitations, skeletal muscle dysfunction in COPD also contributes to poor exercise capacity and increased health care utilization. ${ }^{1}$ Muscle weakness in COPD may be due to multiple factors, including deconditioning, systemic inflammation, and oxidant stress.

Vitamin D insufficiency and deficiency is highly prevalent in the general population and observational studies in the elderly have demonstrated a link between poor muscle strength and low blood levels of 25-hydroxyvitamin D $(25[\mathrm{OH}] \mathrm{D})$, the major circulating vitamin D metabolite. ${ }^{2,3} 25(\mathrm{OH}) \mathrm{D}$ levels below $50 \mathrm{nmol} / \mathrm{L}(23 \mathrm{ng} / \mathrm{mL})$ have been associated with increased body sway, indicative of poor strength of muscles required for balance. ${ }^{4}$ Additionally, advancing age may be associated with decreased 
vitamin D receptor expression in skeletal muscle. ${ }^{5}$ The authors of a meta-analysis of five randomized controlled trials including 1237 participants concluded that supplemental vitamin D reduced the odds of falling by $22 \%,{ }^{6}$ and the US Preventative Services Task Force recently recommended vitamin $\mathrm{D}$ to prevent falls in at-risk elderly individuals. ${ }^{7}$ The mechanisms by which vitamin D modulates muscle function remain poorly understood, although a randomized trial in 96 female stroke survivors showed that vitamin D supplementation increased the number and size of type II (also referred to as "fast twitch") muscle fibers. ${ }^{8}$

Low 25(OH)D levels are also very common in patients with COPD, particularly in severe COPD. ${ }^{9,10}$ We hypothesized that in patients with severe COPD, vitamin D supplementation would improve skeletal muscle function, as measured by the Short Physical Performance Battery (SPPB) score.

\section{Materials and methods}

Participants from the Minneapolis Veterans Affairs Health Care System were recruited as a convenience sample between January 2009 and October 2011 from outpatient pulmonary clinics and an institutional review board-approved database of patients with COPD. The trial was approved by the local institutional review board, and registered at ClinicalTrials. gov prior to enrollment of the first patient (NCT 00914810). All participants provided their written informed consent.

Inclusion criteria included age $\geq 50$ years, forced expiratory volume in one second $\left(\mathrm{FEV}_{1}\right) /$ forced vital capacity $(\mathrm{FVC}) \leq 70 \%, \mathrm{FEV}_{1} \leq 50 \%$ of predicted, cigarette smoking history $\geq$ than 10 pack-years, and ability to ambulate independently or with the use of an ambulatory assist device, such as a cane or walker. Exclusion criteria included use of $>500 \mathrm{IU} /$ day of supplemental vitamin D, primary diagnosis of asthma, uncompensated congestive heart failure, acute myocardial infarction in the 6 months prior to enrollment, estimated glomerular filtration rate $\leq 45 \mathrm{~mL} / \mathrm{min} / 1.73 \mathrm{~m}^{2}$, expected survival $\leq 6$ months, malignancy treated with chemotherapy and/or radiation in the past 12 months, previously treated cancer now in relapse, metastatic malignancy, psychiatric disease interfering with the patient's judgment, inability to provide informed consent, and any physical condition or diagnosis which the investigators felt would significantly interfere with assessment of muscle function. Pulmonary rehabilitation was not a specific exclusion criterion, but none of the study participants were enrolled in pulmonary rehabilitation during or prior to the trial, largely due to the existence of pulmonary rehabilitation only as a startup pilot project at our facility when this trial was conducted.
Participants who provided informed consent completed the SPPB and St George's Respiratory Questionnaire (SGRQ), and underwent a blood draw. Participants with a SPPB score of 12/12 were additionally excluded at this stage, due to an inability to improve physical performance any further. Subjects were then randomized, using variable block sizes of 2 or 4 , to receive an oral capsule containing either vitamin $\mathrm{D}_{3}$ (cholecalciferol), or identical-appearing placebo, to be taken once daily for 6 weeks. Cholecalciferol was provided at a dose of 2000 IU per day, which was the Institute of Medicine Food and Nutrition Board upper intake level for vitamin D at the time of study initiation. ${ }^{11}$

Investigators, study coordinators, and study participants were blinded to treatment allocation. Patients then returned at 6 weeks and once again performed the SPPB, completed the SGRQ, and underwent a repeat blood draw.

\section{Short Physical Performance Battery}

The primary outcome was change in SPPB score over the 6-week treatment period. The SPPB test was developed by the National Institute of Aging, is well standardized and validated in elderly populations, ${ }^{12,13}$ and has been used in numerous previous trials in the elderly as a simple outcome to assess changes in lower body muscle strength. ${ }^{14}$ Low SPPB scores in the elderly population are associated with a higher risk of nursing home admission, ${ }^{12}$ functional decline and disability, ${ }^{15,16}$ longer hospital length of stay, ${ }^{17}$ rehospitalization, ${ }^{18}$ and mortality. ${ }^{12,15}$ SPPB scores are lower in COPD patients than in age-matched controls, ${ }^{19}$ and lower SPPB scores are associated with decreased quadriceps strength in COPD patients. ${ }^{20}$

The SPPB consists of three maneuvers to assess balance, $4 \mathrm{~m}$ gait speed, and chair stands (Table 1). Each of the three performance measures is assigned a score ranging from 0 to 4 , with 4 indicating the highest level of performance and 0 indicating inability to complete the test. A summary score (range $0-12$ ) is subsequently calculated by adding the three scores. Scores of 0-3, 4-6, 7-9, and 10-12 are, respectively, classified as severe, moderate, mild, and minimal lower extremity limitation. ${ }^{12}$ We followed the procedures for administering the SPPB as published ${ }^{12}$ and made available online by the National Institute of Aging (http://www.grc.nia.nih.gov/ branches/ledb/sppb/). We chose the SPPB score over the more conventional pulmonary study outcome of 6-minute walk distance, due to multiple organ effects on 6-minute walk distance, including the pulmonary, cardiac, and skeletal muscle systems, whereas the SPPB is not expected to be affected by cardiac or pulmonary limitations. Therefore, the 
Table I Short Physical Performance Battery components and scoring

\begin{tabular}{ll}
\hline Balance & \\
Side-by-side stand $>10$ seconds & I point \\
Semi-tandem stand $>10$ seconds & I point \\
Tandem stand & \\
$\geq 10$ seconds & 2 points \\
$3.00-9.99$ seconds & I point \\
$\leq 2.99$ seconds & 0 points \\
4 m gait speed & \\
Unable to walk & 0 points \\
$>8.70$ seconds & I point \\
$6.21-8.70$ seconds & 2 points \\
$4.82-6.20$ seconds & 3 points \\
$<4.82$ seconds & 4 points \\
Chair stands & \\
Unable to perform maneuver or $>60$ seconds to complete & 0 points \\
$\geq 16.70$ seconds & I point \\
I3.70-16.69 seconds & 2 points \\
II.20-13.69 seconds & 3 points \\
$<11.2$ seconds & 4 points \\
\hline
\end{tabular}

SPPB focuses on the hypothesized primary organ affected by our vitamin D intervention, ie, skeletal muscle. We also chose SPPB over more conventional skeletal muscle outcomes such as dynamometry, because of the simplicity of administering the test without specialized equipment or training.

\section{St George's Respiratory Questionnaire}

All participants were asked to complete the SGRQ ${ }^{21}$ at baseline and at the end of the 6-week intervention period. The SGRQ is a well validated self-administered questionnaire that measures health-related quality of life specifically related to pulmonary disease. The SGRQ contains 50 questions aimed at three domains, ie, respiratory symptoms, limitations of activity from breathlessness, and the impact of lung disease on social and psychological functioning. The SGRQ is scored on a scale of $0-100$, with a score of 100 reflecting the most severe symptoms, limitations, and psychosocial impact of respiratory disease.

\section{Serum samples}

Blood samples were drawn by phlebotomists and centrifuged by research staff at $2200 \mathrm{rpm}$ for 15 minutes. Serum was then stored at $-70^{\circ} \mathrm{C}$ until all participants completed the study. Serum $25(\mathrm{OH}) \mathrm{D}$ analysis was performed by the Immunochemical Core Laboratory at the Mayo Clinic (Rochester, MN), using liquid chromatography tandem mass spectroscopy, analysis of which provides values for both $25(\mathrm{OH}) \mathrm{D} 2$ (the form generated by ultraviolet irradiation of ergosterol from yeast and present in ergocalciferol-containing supplements) and
25(OH)D3 (the form generated by solar ultraviolet B exposure and present in cholecalciferol-containing supplements). These two results are summed to generate the total $25(\mathrm{OH}) \mathrm{D}$ level used in clinical assessments and reported in this study. For $25(\mathrm{OH}) \mathrm{D} 2$, intra-assay coefficients of variation are $4.4 \%$, $3.3 \%$, and $4.2 \%$ at 14,41 , and $124 \mathrm{ng} / \mathrm{mL}$, respectively, and interassay coefficients of variation are $6.1 \%, 6.2 \%$, and $4.7 \%$ at 15,43 , and $128 \mathrm{ng} / \mathrm{mL}$, respectively. For $25(\mathrm{OH}) \mathrm{D} 3$, intraassay coefficients of variation are $3.8 \%, 2.4 \%$, and $4.7 \%$ at 25,54 , and $140 \mathrm{ng} / \mathrm{mL}$, respectively; interassay coefficients of variation are $6.4 \%, 6.8 \%$, and $5.0 \%$ at 24,52 , and $140 \mathrm{ng} / \mathrm{mL}$, respectively.

\section{Sample size and power calculations}

A clinically meaningful difference in SPPB score is not fully agreed upon, although many consider a change in 1.0 point to be significant. ${ }^{14}$ The SPPB has not been widely used in intervention studies among patients with COPD, so a clinically meaningful difference specific to COPD has not been established. At the time of trial planning, there were no published data regarding the standard deviation of SPPB scores over time in patients with COPD. Therefore, we utilized data from an elderly non-COPD population showing a standard deviation of 1.5 SPPB points, and we elected to power this as a pilot study to detect a difference of 1.5 SPPB points between the two treatment arms. Using these assumptions, a study with $80 \%$ power and a two-tailed alpha error rate of 0.05 required sample sizes of 17 participants per arm.

\section{Data analysis}

The primary analysis compared 6-week changes in SPPB scores between the two groups (vitamin D supplementation versus placebo). Participants who did not complete the study were not included in the analysis, because we had only baseline prerandomization data for these participants. Changes in SPPB scores were calculated for each participant, using the 6-week SPPB score and subtracting the baseline SPPB score. We used $t$-tests to compare the mean change in SPPB score in the vitamin D arm compared with the placebo arm. Secondary analyses included 6-week change in SGRQ scores and 25(OH)D levels. Because of imbalances in baseline SPPB and SGRQ scores, we also performed linear regression analyses that included baseline SPPB and baseline SGRQ scores as covariates.

\section{Results}

Of 41 participants who provided informed consent, 39 met the study entry criteria and were randomized. During follow-up, 
two participants withdrew from the placebo group (one because of relocation out of the state, one as a result of family bereavement and unavailability for follow-up) and one participant withdrew from the intervention arm (due to prolonged hospitalization and unavailability for follow-up). A total of 18 participants in each arm attended the 6-week follow-up visit (Figure 1).

Our participants were all Caucasian males, with a mean age of 68 years and severe COPD (Table 2). Baseline characteristics were reasonably well balanced, given the relatively small sample size. In the intervention arm, compared with placebo, there were fewer active smokers, fewer subjects with coronary artery disease, better SPPB scores, and better SGRQ scores. The baseline SPPB score distribution is shown in Figure 2.

The overall mean baseline $25(\mathrm{OH}) \mathrm{D}$ level was $23.5 \mathrm{ng} / \mathrm{mL}$, with values being similar in the two treatment arms $(24.4 \mathrm{ng} / \mathrm{mL}$ in the placebo arm versus $22.6 \mathrm{ng} / \mathrm{mL}$ in the vitamin $\mathrm{D}$ arm; $P=0.60$ ). Twenty-six percent of the participants had levels $\geq 30 \mathrm{ng} / \mathrm{mL}, 30 \%$ had levels $\geq 20 \mathrm{ng} / \mathrm{mL}$ but $<30 \mathrm{ng} / \mathrm{mL}$, and $41 \%$ had levels $<20 \mathrm{ng} / \mathrm{mL}$. Only two patients had baseline 25(OH)D levels $<10 \mathrm{ng} / \mathrm{mL}$. Pill counts demonstrated that $99 \%$ and $98.5 \%$ of the prescribed doses were actually consumed in the placebo and vitamin D arms, respectively.

After 6 weeks of receiving the study drug, the vitamin D supplementation arm experienced a significant increase in mean 25(OH)D levels to a level of $32.6 \pm 8.2 \mathrm{ng} / \mathrm{mL}$, while the placebo arm had a mean level of $22.1 \pm 10.1 \mathrm{ng} / \mathrm{mL}$. Despite increased $25(\mathrm{OH}) \mathrm{D}$ levels in the intervention arm, there were no significant improvements in SPPB or SGRQ scores (Table 3 ). However, the $95 \%$ confidence intervals of these differences did not exclude the possibility of a clinically meaningful difference of 1.0 point in SPPB scores or a clinically meaningful change in SGRQ scores of 4 points. ${ }^{22}$ A linear regression model was also performed to adjust for baseline imbalances in SPPB and SGRQ scores and resulted in similar nonsignificant results (Table 3).

None of the three components of the SPPB (balance, chair stands, gait speed) nor the three domains of the SGRQ (symptoms, activity, impact) were significantly different between treatments. The proportion of patients who had minimal clinically important changes in outcome was not different between the placebo and vitamin $\mathrm{D}$ arms for either SPPB (50\% and 50\%, respectively; $P=1.0$ ) or for SGRQ $(23.5 \%$ and $33.3 \%$, respectively; $P=0.70$ ). There were no studyrelated serious adverse events in either treatment arm.

\section{Discussion}

To our knowledge, we provide the first report of a randomized controlled trial piloting the effects of vitamin D supplementation on a primary outcome of physical performance in COPD. Our vitamin D intervention significantly

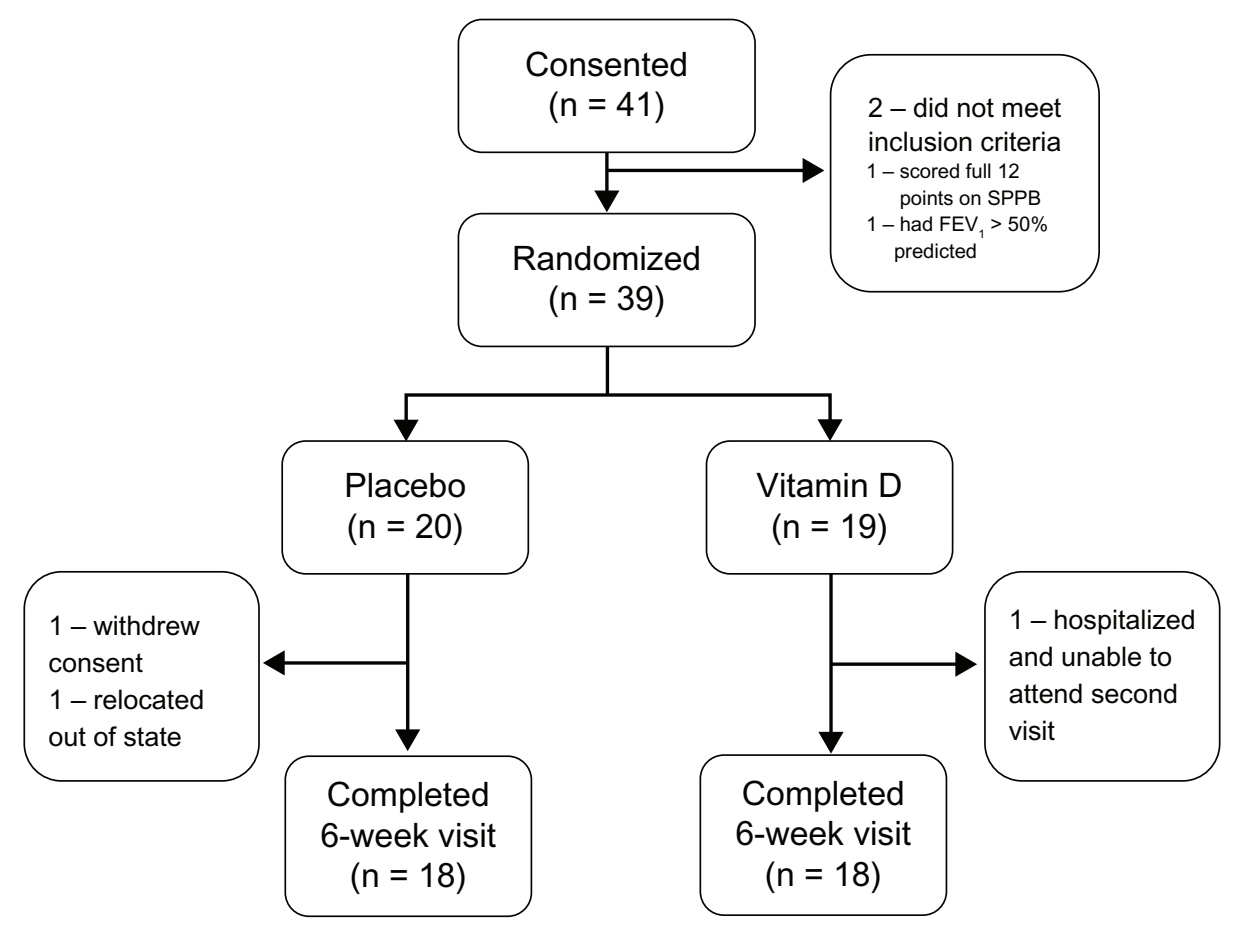

Figure I Study flow diagram.

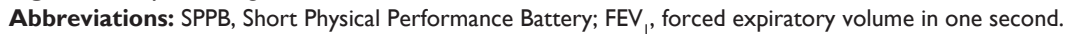


Table 2 Participant characteristics

\begin{tabular}{|c|c|c|}
\hline & $\begin{array}{l}\text { Placebo } \\
\text { group } \\
(n=18)\end{array}$ & $\begin{array}{l}\text { Vitamin D } \\
\text { group } \\
(n=18)\end{array}$ \\
\hline Age, years & $68 \pm 8$ & $67.6 \pm 7$ \\
\hline Male, n (\%) & $18(100)$ & $18(100)$ \\
\hline Caucasian, n (\%) & $18(100)$ & $18(100)$ \\
\hline $\mathrm{FEV}_{1}, \mathrm{~L}$ & $0.99 \pm 0.27$ & $1.09 \pm 0.37$ \\
\hline $\mathrm{FEV}_{1}$, \% predicted & $31 \pm 8$ & $35 \pm 10$ \\
\hline FVC, L & $2.42 \pm 0.75$ & $2.58 \pm 0.63$ \\
\hline FVC, \% predicted & $56 \pm 17$ & $61 \pm 13$ \\
\hline Currently smoking, n (\%) & II (6I) & $7(39)$ \\
\hline Pack-year smoking history & $69 \pm 42$ & $72 \pm 46$ \\
\hline Coronary disease, n (\%) & $9(50)$ & $5(28)$ \\
\hline Heart failure, $n(\%)$ & $3(17)$ & $2(I I)$ \\
\hline Pulmonary hypertension, $\mathrm{n}(\%)$ & 0 & $I(6)$ \\
\hline Hypertension, n (\%) & $10(56)$ & $12(67)$ \\
\hline Osteoarthritis, n (\%) & $9(50)$ & $10(56)$ \\
\hline Rheumatoid arthritis, n (\%) & $0(0)$ & I (6) \\
\hline Living independently, n (\%) & $18(100)$ & $18(100)$ \\
\hline $\begin{array}{l}\text { Estimated (self-report) hours of sun } \\
\text { exposure per week over the last month }\end{array}$ & $11 \pm 9$ & $10 \pm 12$ \\
\hline Long-acting beta agonist, n (\%) & $17(94)$ & $15(83)$ \\
\hline Inhaled corticosteroid, n (\%) & $13(72)$ & $15(83)$ \\
\hline Long-acting anticholinergic, n (\%) & $13(72)$ & $9(50)$ \\
\hline $\begin{array}{l}\text { Number of respiratory hospitalizations } \\
\text { in the last year }\end{array}$ & $1.3 \pm 2.5$ & $0.7 \pm 1.3$ \\
\hline $\begin{array}{l}\text { Weeks since last use of prednisone/ } \\
\text { antibiotic for COPD }\end{array}$ & $19.7 \pm 24.9$ & $14.0 \pm 17.6$ \\
\hline
\end{tabular}

Note: Values are expressed as the mean \pm standard deviation or $\mathrm{n}(\%)$. Abbreviations: COPD, chronic obstructive pulmonary disease; FEV , forced expiratory volume in one second; FVC, forced vital capacity.

increased 25(OH)D levels by $10.5 \mathrm{ng} / \mathrm{mL}$ to a mean level of $32.6 \mathrm{ng} / \mathrm{mL}$, a level widely considered as normal. ${ }^{23}$ Despite this significant increase, vitamin D supplementation did not significantly improve SPPB or SGRQ scores. The mean 0.3 point greater improvement in SPPB scores observed in the vitamin D arm had a 95\% confidence interval ranging from -0.8 to 1.5 points, so did not exclude the possibility of a meaningful change of 1.0 point in SPPB scores. ${ }^{14}$ Likewise, the confidence interval for SGRQ effects did not exclude the potential for a clinically meaningful effect. Based on our data regarding the standard deviation of SPPB scores in COPD, a definitive randomized trial to detect a smaller change in SPPB of 1.0 point would require a sample size of 59 patients in each arm; 259 patients in each arm would be needed to detect an even smaller, but potentially meaningful, SPPB change of 0.5 points. ${ }^{14}$ Therefore, a larger randomized controlled trial would be needed in order to draw more definitive conclusions regarding the effects of vitamin D on physical performance and respiratory health status in severe COPD.

We chose to utilize the SPPB score to assess physical performance, specifically lower extremity strength, because of its widespread use in the geriatric literature, standardized application, ease of administration by nonphysiologists, and established relationship with clinically relevant outcomes, such as mortality, in the geriatric literature. Based on mechanistic studies, we also hypothesized that vitamin D would affect the fast, powerful type II muscle fibers more than the type I muscle fibers that affect endurance. Given the focus of the SPPB on three tests of lower extremity skeletal muscle power and strength, the SPPB appeared to be an appropriate outcome measure. Despite the attractive features of the SPPB test, it has not been widely used in COPD trials.

Our study sample had severe COPD, with a mean $\mathrm{FEV}_{1}$ of approximately $1 \mathrm{~L}$, yet had SPPB scores considered to reflect only mild lower extremity strength impairment. Therefore, a limitation of our study is that our patient sample may not have been significantly impaired enough to derive a potential vitamin $\mathrm{D}$ benefit. It would be reasonable to hypothesize that those with lower baseline SPPB scores might be more likely

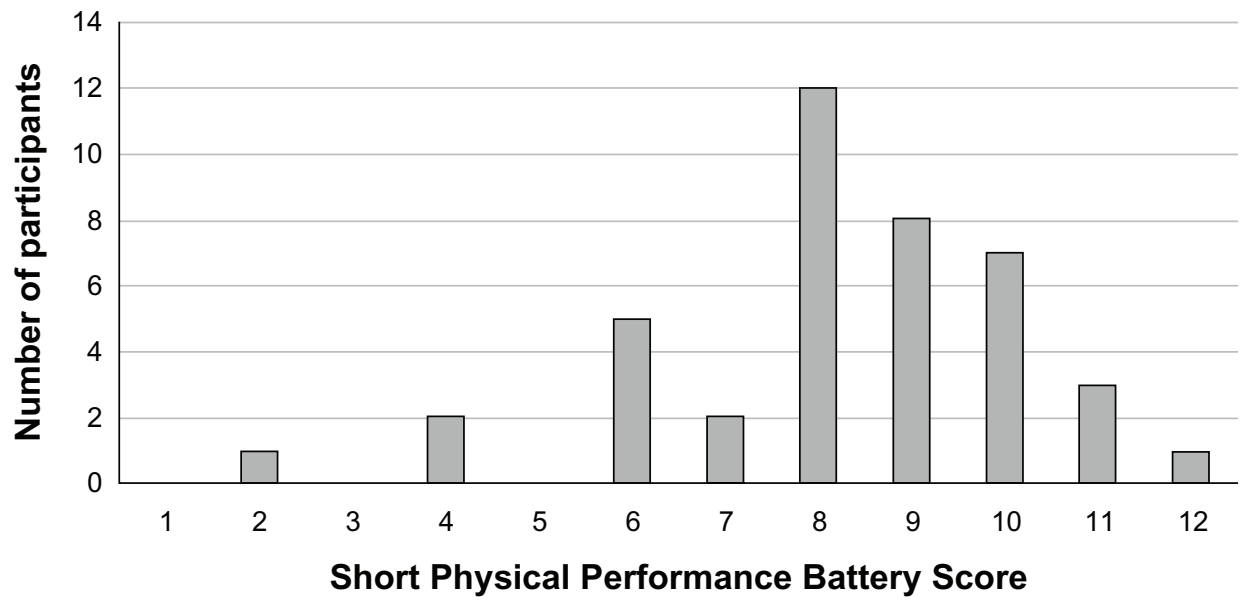

Figure 2 Distribution of baseline Short Physical Performance Battery Scores. 
Table 3 Primary and secondary outcome results^

\begin{tabular}{|c|c|c|c|}
\hline & $\begin{array}{l}\text { Placebo group } \\
(n=18)\end{array}$ & $\begin{array}{l}\text { Vitamin D group } \\
(n=18)\end{array}$ & $\begin{array}{l}\text { Difference } \\
(95 \% \mathrm{Cl})\end{array}$ \\
\hline \multicolumn{4}{|l|}{ Primary outcome } \\
\hline SPPB baseline & $7.8 \pm 1.6$ & $8.8 \pm 1.8$ & \\
\hline SPPB 6 weeks & $8.4 \pm 2.6$ & $9.7 \pm 1.2$ & \\
\hline SPPB change (unadjusted) & $0.6 \pm 1.7(-0.2$ to 1.5$)$ & $0.9 \pm 1.6(0.1$ to 1.8$)$ & $0.3(-0.8$ to 1.5$)$ \\
\hline SPPB change (adjusted for baseline SPPB) & & & $0.6(-0.5$ to 1.8$)$ \\
\hline \multicolumn{4}{|l|}{ Secondary outcomes } \\
\hline SGRQ total baseline* & $64 \pm 15$ & $53 \pm 18$ & \\
\hline SGRQ total 6 weeks ${ }^{\#}$ & $63.8 \pm 13.7$ & $55.6 \pm 18.3$ & \\
\hline SGRQ change ${ }^{\infty}$ (unadjusted) & $-1 \pm 6.9(-4.6$ to 2.6$)$ & $1.3 \pm 5.6(-1.8$ to 4.3$)$ & $2.3(-2.3$ to 6.9$)$ \\
\hline SGRQ change (adjusted for baseline SGRQ) & & & I.I $(-3.6$ to 5.8$)$ \\
\hline $25(\mathrm{OH}) \mathrm{D}$ baseline, ${ }^{\#} \mathrm{ng} / \mathrm{mL}$ & $24.4 \pm 10.5$ & $22.6 \pm 10.5$ & \\
\hline $25(\mathrm{OH}) \mathrm{D}$ at 6 weeks, ${ }^{\#} \mathrm{ng} / \mathrm{mL}$ & $22.1 \pm 10.1$ & $32.6 \pm 8.2$ & \\
\hline $25(\mathrm{OH}) \mathrm{D}$ change, ${ }^{\#} \mathrm{ng} / \mathrm{mL}$ & $-1.8 \pm 3.1(-3.4$ to -0.3$)$ & $8.7 \pm 5.5(5.7$ to || .6$)$ & $10.5(7.43$ to I3.6I) \\
\hline
\end{tabular}

Notes: 'Data available for 36 patients unless otherwise stated; *data available for 33 patients; ${ }^{*}$ data available for 34 patients; ${ }^{\infty}$ data available for 32 patients. Data are expressed as the mean \pm standard deviation $(95 \% \mathrm{Cl})$.

Abbreviations: Cl, confidence interval; SPPB, Short Physical Performance Battery; SGRQ, St George's Respiratory Questionnaire; 25(OH)D, serum 25-hydroxyvitamin D level.

to benefit from potential skeletal muscle-altering therapies such as vitamin D. Due to the small number of patients with more severe SPPB impairment, we were unable to conduct a subset analysis to explore this hypothesis. However, a previous randomized trial of 176 patients with COPD (mean FEV $52 \%$ of predicted) found that patients randomized to either of two different physical activity interventions experienced improvements in SPPB scores, despite having a near-normal mean baseline SPPB score of $10.6^{24}$ compared with our mean baseline SPPB score of 8.3. These data suggest that COPD patients with high SPPB scores can still derive benefits from interventions targeted at lower extremity strength. Therefore, the mild impairment in baseline SPPB scores in our trial sample is of unclear significance.

Another limitation of our study was the relatively short treatment duration of 6 weeks, which may have been an inadequate amount of time to result in detectable skeletal muscle effects. Vitamin D nuclear receptors have been reported to exist in skeletal muscle, although their exact function is not completely understood. It has been suggested that binding of 1,25 dihydroxyvitamin $\mathrm{D}$ to these nuclear receptors causes a cascade of intracellular signaling and gene transcription of mRNA, leading to de novo protein and skeletal muscle synthesis. ${ }^{25-28}$ It is also postulated that with aging, vitamin D receptor expression decreases and leads to decreased transcription and subsequent decreased skeletal muscle strength. ${ }^{5}$ Further, vitamin D receptor polymorphisms are associated with variations in quadriceps strength in both normal subjects and COPD patients. ${ }^{26,29}$ Given that improvements in skeletal muscle from vitamin $\mathrm{D}$ likely require formation of de novo muscle fibers, particularly type II muscle fibers, ${ }^{8}$ a longer period of supplementation may have been necessary to detect clinical changes, although other short-term randomized trials showed that vitamin D improved body sway after only 8 weeks ${ }^{4}$ and decreased falls over 12 weeks. ${ }^{30}$ Therefore, the duration of treatment needed to detect muscle function effects is not clear. Although we chose a 6 -week duration based on the pilot nature of this study and the short-term studies cited above, longer periods of observation in future studies could improve the ability to detect potential longer-term effects of vitamin $\mathrm{D}$ on skeletal muscle function in patients with COPD. We also note recent data suggesting that previous reports of vitamin D receptor presence in skeletal muscle may have been erroneous due to problems with many of the vitamin $\mathrm{D}$ receptor detection methods. ${ }^{31}$ Such data would suggest that potential vitamin D-mediated skeletal muscle effects, if present, are not mediated by direct effects of vitamin D on skeletal muscle tissue.

Another potential limitation is the dose of vitamin D used. Our dose of $2000 \mathrm{IU} /$ day achieved what is widely considered a normal 25(OH)D level, ${ }^{23}$ but commonly used vitamin D thresholds for defining normal, insufficient, or deficient levels are largely based on studies of bone health and parathyroid hormone concentrations. The optimal 25(OH)D level for potential skeletal muscle benefits remains unknown, although in general population observational studies, decrements in SPPB scores are uncommonly seen in patients with 25(OH)D levels $>30 \mathrm{ng} / \mathrm{mL}^{2,3}$ and falls have been prevented in elderly populations with vitamin $\mathrm{D}$ supplementation to levels of 26-30 ng/mL. ${ }^{30,32,33}$ In addition, a randomized trial that 
administered 500,000 IU of oral vitamin $\mathrm{D}$ as a single annual dose resulted in a 3-month 25(OH)D level of $48 \mathrm{ng} / \mathrm{mL}$ and an increase in falls during that 3 -month period. ${ }^{34}$ Therefore, the available data do not suggest additional skeletal muscle benefits at supranormal 25(OH)D levels. Patients with more severe forms of vitamin $\mathrm{D}$ deficiency $(<10 \mathrm{ng} / \mathrm{mL})$ might be reasonably expected to derive more benefit from supplementation, but our sample was too small to perform a subgroup analysis of such patients. However, future studies might consider selecting such patients or at least planning prespecified and adequately powered analyses of such subgroups.

Randomized trials should ideally adhere to intent-to-treat analyses of all randomized participants. In our trial, three of 39 randomized participants were unable to return for a follow-up visit and therefore provided no outcome data. As such, we could not perform a strict intent-to-treat analysis of all 39 participants. This is the unfortunate case in studies with exercise outcomes, because participants must return to the study center for these assessments (ie, outcomes cannot be assessed by telephone calls nor chart reviews). While we made significant efforts to get every participant to return, three simply could not do so. While a sensitivity analysis is often done in these scenarios (assuming a best or worst case scenario), with our limited power, we did not feel conclusions from such analyses would be of value. Given that there were only two study visits (ie, no data beyond baseline, prerandomization data), last-observation-carried-forward methods for missing data were not appropriate. The reasons for the dropouts do not seem related to physical performance or vitamin D responses, but we cannot exclude the possibility that the dropouts somehow biased our results.

Lastly, we note that our study sample was limited to Caucasian males, largely because of the demographics of the population at our study center. Therefore, our results cannot be extrapolated to non-Caucasians or females.

While our study had these important potential limitations, we must acknowledge the possibility of vitamin D having no effect on physical performance in patients with COPD. In support of such a hypothesis, a recent post hoc subgroup analysis of 50 COPD subjects, who underwent pulmonary rehabilitation during a randomized trial of vitamin $\mathrm{D}$ versus placebo, showed no difference in quadriceps strength in the two arms of the trial. ${ }^{35}$ Additionally, recently published data also showed that the association between vitamin $\mathrm{D}$ levels and quadriceps strength was present in healthy controls, but not in age-matched or gender-matched patients with COPD. ${ }^{36}$ Therefore, while vitamin $\mathrm{D}$ supplementation may improve muscle strength in a general elderly population, patients with COPD may have limited or no benefit as a result of mechanisms such as systemic inflammation, regional tissue hypoxemia, oxidative stress, and vitamin D resistance.

\section{Conclusion}

In conclusion, in this pilot trial of patients with severe COPD, vitamin D 2000 IU/day for 6 weeks significantly increased serum $25(\mathrm{OH}) \mathrm{D}$ levels to a widely accepted normal level of $32.6 \mathrm{ng} / \mathrm{mL}$. Despite this increase, vitamin D supplementation had no major effect on a simple measure of lower extremity physical performance, compared with placebo. Larger, longer-duration trials would be required to assess more definitively the potential effects of vitamin $\mathrm{D}$ on physical performance in COPD. However, our data and other recently published data make such an effect seem less likely.

\section{Acknowledgments}

We thank Patricia Painter and Carrie Earthman for their guidance in protocol development and advice on outcome assessment during trial planning stages. We thank Dennis Niewoehner for feedback on the protocol and manuscript. We also thank the veterans who participated in this trial. Funding for this study was provided by the Minnesota Veterans Medical Research and Education Foundation and the National Institutes of Health, Mayo Clinic CTSA award UL1 RR024150.

\section{Disclosure}

The authors report no conflicts of interest in this work. The views expressed in this paper are those of the authors and do not necessarily reflect the views of the Minneapolis VA Health Care System, the Minnesota Veterans Medical Research and Education Foundation, the Department of Veterans Affairs, the US Government, or the University of Minnesota.

\section{References}

1. Decramer M, Gosselink R, Troosters T, Verschueren M, Evers G. Muscle weakness is related to utilization of health care resources in COPD patients. Eur Respir J. 1997;10:417-423.

2. Bischoff-Ferrari HA, Dietrich T, Orav EJ, et al. Higher 25-hydroxyvitamin D concentrations are associated with better lowerextremity function in both active and inactive persons aged $\geq 60$ y. $A m$ J Clin Nutr. 2004;80:752-758.

3. Wicherts IS, van Schoor NM, Boeke AJ, et al. Vitamin D status predicts physical performance and its decline in older persons. J Clin Endocrinol Metab. 2007;92:2058-2065.

4. Pfeifer M, Begerow B, Minne HW. Vitamin D and muscle function. Osteoporos Int. 2002;13:187-194.

5. Bischoff-Ferrari HA, Borchers M, Gudat F, Durmuller U, Stahelin HB, Dick W. Vitamin D receptor expression in human muscle tissue decreases with age. J Bone Miner Res. 2004;19:265-269. 
6. Bischoff-Ferrari HA, Dawson-Hughes B, Willett WC, et al. Effect of vitamin D on falls: a meta-analysis. JAMA. 2004;291:1999-2006.

7. Moyer VA; on behalf of the US Preventive Services Task Force. Prevention of falls in community-dwelling older adults: US Preventive Services Task Force Recommendation Statement. Ann Intern Med. 2012;157:197-204.

8. Sato Y, Iwamoto J, Kanoko T, Satoh K. Low-dose vitamin D prevents muscular atrophy and reduces falls and hip fractures in women after stroke: a randomized controlled trial. Cerebrovasc Dis. 2005;20:187-192.

9. Janssens W, Bouillon R, Claes B, et al. Vitamin D deficiency is highly prevalent in COPD and correlates with variants in the vitamin D-binding gene. Thorax. 2010;65:215-220.

10. Kunisaki KM, Niewoehner DE, Connett JE; COPD Clinical Research Network. Vitamin D levels and risk of acute exacerbations of chronic obstructive pulmonary disease: a prospective cohort study. Am J Respir Crit Care Med. 2012;185:286-290.

11. Institute of Medicine, Standing Committee on the Scientific Evaluation of Dietary Reference Intakes, Food and Nutrition Board. Dietary reference intakes for calcium, phosphorus, magnesium, vitamin D, and fluoride. 1997. Available from: http://www.ncbi.nlm.nih.gov/books/ NBK109825/. Accessed January 15, 2013.

12. Guralnik JM, Simonsick EM, Ferrucci L, et al. A short physical performance battery assessing lower extremity function: association with self-reported disability and prediction of mortality and nursing home admission. J Gerontol. 1994;49:M85-M94.

13. Guralnik JM, Ferrucci L, Pieper CF, et al. Lower extremity function and subsequent disability: consistency across studies, predictive models, and value of gait speed alone compared with the short physical performance battery. J Gerontol A Biol Sci Med Sci. 2000;55:M221-M231.

14. Perera S, Mody SH, Woodman RC, Studenski SA. Meaningful change and responsiveness in common physical performance measures in older adults. J Am Geriatr Soc. 2006;54:743-749.

15. Corsonello A, Lattanzio F, Pedone C, et al; on behalf of The Pharmacosurveillance In The Elderly Care Pvc Study Investigators RA. Prognostic significance of the Short Physical Performance Battery in older patients discharged from acute care hospitals. Rejuvenation Res. 2012;15:41-48.

16. Guralnik JM, Ferrucci L, Simonsick EM, Salive ME, Wallace RB. Lower-extremity function in persons over the age of 70 years as a predictor of subsequent disability. $N$ Engl J Med. 1995;332:556-561.

17. Volpato S, Cavalieri M, Guerra G, et al. Performance-based functional assessment in older hospitalized patients: feasibility and clinical correlates. J Gerontol A Biol Sci Med Sci. 2008;63:1393-1398.

18. Volpato S, Cavalieri M, Sioulis F, et al. Predictive value of the Short Physical Performance Battery following hospitalization in older patients. J Gerontol A Biol Sci Med Sci. 2011;66:89-96.

19. Eisner MD, Blanc PD, Yelin EH, et al. COPD as a systemic disease: impact on physical functional limitations. Am J Med. 2008;121: 789-796.
20. Singer J, Yelin EH, Katz PP, et al. Respiratory and skeletal muscle strength in chronic obstructive pulmonary disease: impact on exercise capacity and lower extremity function. J Cardiopulm Rehabil Prev. 2011;31:111-119.

21. Jones PW, Quirk FH, Baveystock CM. The St George's Respiratory Questionnaire. Respir Med. 1991;85 Suppl B:25-31.

22. Jones PW. St George's Respiratory Questionnaire: MCID. COPD. 2005;2:75-79.

23. Holick MF. Vitamin D deficiency. N Engl J Med. 2007;357:266-281.

24. Berry MJ, Rejeski WJ, Miller ME, et al. A lifestyle activity intervention in patients with chronic obstructive pulmonary disease. Respir Med. 2010;104:829-839.

25. Geusens P, Vandevyver C, Vanhoof J, Cassiman JJ, Boonen S, Raus J. Quadriceps and grip strength are related to vitamin $D$ receptor genotype in elderly nonobese women. J Bone Miner Res. 1997;12:2082-2088.

26. Costa EM, Blau HM, Feldman D. 1,25-dihydroxyvitamin D3 receptors and hormonal responses in cloned human skeletal muscle cells. Endocrinology. 1986;119:2214-2220.

27. De Boland AR, Boland RL. Non-genomic signal transduction pathway of vitamin D in muscle. Cell Signal. 1994;6:717-724.

28. Norman AW, Nemere I, Zhou LX, et al. 1,25(OH)2-vitamin D3, a steroid hormone that produces biologic effects via both genomic and nongenomic pathways. J Steroid Biochem Mol Biol. 1992;41:231-240.

29. Hopkinson NS, Li KW, Kehoe A, et al. Vitamin D receptor genotypes influence quadriceps strength in chronic obstructive pulmonary disease. Am J Clin Nutr. 2008;87:385-390.

30. Bischoff HA, Stahelin HB, Dick W, et al. Effects of vitamin D and calcium supplementation on falls: a randomized controlled trial. J Bone Miner Res. 2003;18:343-351.

31. Wang Y, DeLuca H. Is the vitamin D receptor found in muscle? Endocrinology. 2011;152:354.

32. Broe KE, Chen TC, Weinberg J, Bischoff-Ferrari HA, Holick MF, Kiel DP. A higher dose of vitamin d reduces the risk of falls in nursing home residents: a randomized, multiple-dose study. J Am Geriatr Soc. 2007;55:234-239.

33. Pfeifer M, Begerow B, Minne HW, Abrams C, Nachtigall D, Hansen C. Effects of a short-term vitamin D and calcium supplementation on body sway and secondary hyperparathyroidism in elderly women. J Bone Miner Res. 2000;15:1113-1118.

34. Sanders KM, Stuart AL, Williamson EJ, et al. Annual high-dose oral vitamin D and falls and fractures in older women: a randomized controlled trial. JAMA. 2010;303:1815-1822.

35. Hornikx M, Van Remoortel H, Lehouck A, et al. Vitamin D supplementation during rehabilitation in COPD: a secondary analysis of a randomized trial. Respir Res. 2012;13:84.

36. Jackson AS, Shrikrishna D, Kelly JL, et al. Vitamin D and skeletal muscle strength and endurance in chronic obstructive pulmonary disease. Eur Respir J. 2013;41:309-316.
International Journal of COPD

\section{Publish your work in this journal}

The International Journal of COPD is an international, peer-reviewed journal of therapeutics and pharmacology focusing on concise rapid reporting of clinical studies and reviews in COPD. Special focus is given to the pathophysiological processes underlying the disease, intervention programs, patient focused education, and self management protocols.

\section{Dovepress}

This journal is indexed on PubMed Central, MedLine and CAS. The manuscript management system is completely online and includes a very quick and fair peer-review system, which is all easy to use. Visit http://www.dovepress.com/testimonials.php to read real quotes from published authors. 